\title{
Mental State Language Experiences of Chinese Preschool Children in Their Interactions with Peers and Educators during Free Play
}

\author{
Zhenyu Yang ${ }^{1}$, Jiangbo Bu ${ }^{1}$, Fei Han ${ }^{2}$ \\ ${ }^{1}$ Zhejiang Normal University \\ ${ }^{2}$ Xingyuan Child Care Centre and Preschool \\ China
}

\begin{abstract}
Mental state language (MSL) describes people's psychological states including desires, emotions, conceptions and cognition. This study investigated the feature of 12 Chinese preschoolers' MSL experiences in their interactions with peers and educators during free play. Naturalistic language data from the interactions were collected and analyzed. The prevalence, types, and referents of MSL use across three age groups (3-4, 4-5, 5-6 years) were examined. The results show that the group of 5- 6 years generated significantly more MSL in all types than the two younger groups. The type of "desire" dominated the children's MSL use and "emotions" hardly appeared in the interactions. The expressions of "perception" and "cognition" were more likely to occur in the language of 5-6 years. The educators used more MSL containing different types of MSL terms than the peers. However, the referents of $M L S$ of the focus children were mainly referred to their peers. These findings indicate that 5-6 years may be the critical period for Chinese children's MSL development. Educators and peers contributed to these children's MSL experiences significantly though their roles varied across the age groups. Implications of these finding are discussed.
\end{abstract}

\section{Introduction}

Research shows that preschool children become increasingly capable in using mental state language (MSL) referring to people's inner states including emotion, perception, desire, and cognition [1][2]. Children's use of MSL is associated with their development of cognitive and linguistic skills as well as socioemotional experiences, which have implications with their schooling performance in the future [1][3][4][5]. Plenty of MSL studies undertaken from the perspective of adults' (mothers and teachers) language use and identified the positive correlations between children's MSL development and adults' MSL input in their child-addressed talk [6][7][8]. The factors relating to mothers and educators' personal background (e.g. educational level) are found to significantly affect the quantity and quality (types) of their MSL use. To date, most existing research was carried out in Western countries and focused on adults' language use.
The studies undertaken in Chinese context and from children's point of view are limited. This study is designed to explore Chinese preschool children's MSL use in their interactions with peers and educators during free play. Children spend considerable time interacting with their peers and educators in preschools and research suggests that free play facilitates children's MSL for expressing thoughts, perceptions, desires and emotions[7][9][10]. The results of the study would increase our understanding of the feature of Chinese preschool children's MSL use and the factors that impact their MSL language experiences from children's perspective.

\section{Literature Review}

Research suggests that the exposure to MSL in children's early years promotes their understanding about people's "inner individuality"[1][3], language skills [4][5] and social competence[7][11]. It is regarded that this language supports children's growing ability to discuss thoughts, feelings in their social interactions, and lays crucial foundations for their reading and comprehension skills that may predict their later language and academic achievements. For example, Barnes and Dickinson [5] explored the relations between teachers' mental verbs use and children' vocabulary growth and found that teacher' MSL conversations with children that included rich academic vocabulary terms about observation, information, support and nourishment could stimulate children' word learning opportunities relating to high-order thinking. The characteristics of MSL use across different age groups are wellexplored in the literature. Evidence from relevant research shows that children begin to use MSL terms generally at about two years old [12][13]. The age of four years is an important milestone for children's MSL development, because their ability to use MSL will be improved rapidly afterwards[13]. Research suggests that utterances about desire appeared frequently in two-year-old children's language whereas cognitive terms rarely uttered until four years. Interestingly, children' language relating to emotions is so little that researchers proposed that there is a more complex psychological mechanism relating to cultural conventions that discourage direct 
expressions on emotion in many countries[14]. The trajectory of these MSL developments of children mainly is identified in English culture. The characteristics of Chinese children' MSL use remain unexplored. . A strand of research focused on the factors that impact the feature of children's MSL use. Researchers explored the relationship between children's MSL use and their performance on Theory of Mind (TOM), a set of tasks showing children's competence of understanding oneself and others' internal psychological traits and confirmed the interrelated relationship between these two variables [1][4][15]. In addition, the input of MSL from adults in children's daily language environment is closely connected with children's MSL development. In some observational studies, maternal MSL have been found to be the predicting variable influencing children's MSL development in home context[6][15]. Children acquire rich MSL lexical items and gain the opportunities for using MSL with their mothers who use MSL frequently[7][8]. For example, Brown et al [6] explored the differences in the interactions between children and their friends, siblings and mothers and found that mothers provided more MSL than friends and siblings[6]. Similarly, some studies reported that MSL produced by educators can foster children MSL development in preschool context[16]. Researchers assessed the educators' input of MSL and children's output of MSL and revealed the positive correlations between these two variables[5].The factors relating to activity contexts and educators' culture background significantly influence the types of educators' MSL use[17].For example, Sheng et al (2021) compared eight Chinese educators' MSL use in their interactions with infants in structured and free play and found that structured play triggered more MSL utterances than free play [17]. Degotardi et al [2] conducted a comparative study between Chinese and Australian educators' MSL use in nurseries and discovered cultural differences between these two cohorts. Australian educators generally used more MSL than Chinese educators, and their MSL referents were more likely to refer to different people (children, self or joint) whereas Chinese educators used more MSL for desire expressions, and their MSL predominately referred to children[2]. To conclude, researchers investigated the characteristics of children's MSL development that is associated with mothers and educators' language input. Such research was mostly undertaken in Western countries addressed the language used in the interactions between children and adults. Little research undertaken in Chinese context or from children's perspective to explore MSL in both child- adult and child-child interactions. This study differs from the previous research through the investigation on Chinese preschool children's MSL use in their interactions with peers and educators in preschool context. This study seeks to address the following research questions:

- What are the characteristics of Chinese preschool children's use of MSL in their interactions with peers and educators?

- what is the nature of Chinese children's MSL experiences across different ages groups (3-4, 45 , and 5-6 years)?

\section{Methodology}

Participants and data collection - The data of this study were extracted from a larger corpus study project "Chinese children's early language experiences" (CCELE) that explores the language experiences of Chinese young children (0-6 years) created through the interactions between the children and their parents, educators and peers. The participant of this study consists of 12 focus children from three age groups - three, four and five years groups (3-4 years, 4-5 years, 5-6 years) with four children in each group. These children were randomly chosen with the criterion of being physically and mentally healthy from the childcare centers that are at the same quality level in Hangzhou City, Zhejiang Province, China. The focus children's conversations with their peers and educators during morning free play in their preschools (30 minutes) were video recorded and transcribed verbatim. The ethics of the study was examined and granted by the Ethics Committee of Zhejiang Normal University. Informed consent was obtained from the focus children' parents, participating educators, other staff, and the parents of other children who might be included in the video record.

\subsection{Participants and data collection}

The coding scheme of this study draws on theories of MSL. It includes the following steps.

3.2.1. Organization of texts of language. The transcribed text of language was broken into clauses, each of which contains a subject (explicit or implicit) and a verb.

3.2.2. Identifications of MSL terms. The text of language was examined clause by clause to determine whether it is MSL and what type of MSL it is. The details of the categories of MSL are listed in Table 1.

3.2.3. Clarification of MSL referent. The identified MSL was further examined according to its referent, namely peer, educator, self or joint. The examples of the different MSL referent are presented in Table 2. 
Table 1. Description of MSL types

\begin{tabular}{|c|l|l|}
\hline MSL terms & \multicolumn{1}{|c|}{ Descriptors } & \multicolumn{1}{|c|}{ Examples } \\
\hline emotion & $\begin{array}{l}\text { Refer to emotions such } \\
\text { "happy", "sad", } \\
\text { "cranky", "angry", } \\
\text { "frustrated". }\end{array}$ & $\begin{array}{l}\text { You're feeling } \\
\text { sad. } \\
\text { Are you cranky? }\end{array}$ \\
\hline desire & $\begin{array}{l}\text { Refer to desires such as } \\
\text { "want", "like", "love". }\end{array}$ & $\begin{array}{l}\text { I like this book. } \\
\text { I want to drink } \\
\text { some water. }\end{array}$ \\
\hline perception & $\begin{array}{l}\text { Refer to perception } \\
\text { processes such as } \\
\text { "see", "hear", "feel", } \\
\text { "taste". }\end{array}$ & $\begin{array}{l}\text { It feels soft. } \\
\text { I can smell our } \\
\text { lunch. }\end{array}$ \\
\hline cognition & $\begin{array}{l}\text { Refer to cognitive } \\
\text { processes such as } \\
\text { "remember", "think", } \\
\text { "know". }\end{array}$ & $\begin{array}{l}\text { Do } \\
\text { remember? you } \\
\text { I think you are } \\
\text { right. }\end{array}$ \\
\hline
\end{tabular}

Table 2. MSL referent types and examples

\begin{tabular}{|c|l|}
\hline MSL referent & \multicolumn{1}{|c|}{ Examples } \\
\hline Child & $\begin{array}{l}\text { I would like to tell you a little } \\
\text { secret. }\end{array}$ \\
\hline Educator & $\begin{array}{l}\text { Teacher, I don't want to play with } \\
\text { the slide. }\end{array}$ \\
\hline Self & I have to think of a way. \\
\hline Joint & none \\
\hline
\end{tabular}

The coded data were calculated according to MSL types and referent types as listed above. As the number of total language varied across the cases, the proportion of MSL rather than number of MSL clauses was used. The proportion was calculated by dividing the number of MSL, each type of MSL, and referent of MSL by total clauses.

\section{Results}

The Table 3 presents the general features of MSL use in child-child and child-educator interactions. In total, 367 MSL were identified from the 3578 clauses generated by the focus children's interactions with peers and educators during the 30 minutes' free play.

Table 3. General features of MSL use across Three Age Groups

\begin{tabular}{rccccccc}
\hline $\begin{array}{c}\text { age } \\
\text { group }\end{array}$ & participants & $\begin{array}{c}\text { Total } \\
\text { messages }\end{array}$ & sum(MSL) & emotion & desire & perception & cognitive \\
\hline \multirow{2}{*}{$3 \sim 4$} & self & 680 & $49(7.2 \%)$ & $1(0.1 \%)$ & $26(3.8 \%)$ & $14(2.0 \%)$ & $8(1.2 \%)$ \\
years & peers & 253 & $15(5.9 \%)$ & $1(0.3 \%)$ & $5(1.9 \%)$ & $6(2.3 \%)$ & $3(1.1 \%)$ \\
& educators & 263 & $22(8.4 \%)$ & $0(0 \%)$ & $6(2,2 \%)$ & $13(4.9 \%)$ & $3(1.1 \%)$ \\
\hline \multirow{2}{*}{$4 \sim 5$} & self & 648 & $50(7.7 \%)$ & $1(0.1 \%)$ & $22(3.3 \%)$ & $13(2.0 \%)$ & $14(2.1 \%)$ \\
years & peers & 271 & $18(6.6 \%)$ & $0(0 \%)$ & $10(3.6 \%)$ & $5(1.8 \%)$ & $3(1.1 \%)$ \\
& educators & 219 & $19(8.6 \%)$ & $0(0 \%)$ & $5(2.2 \%)$ & $11(5.0 \%)$ & $3(1.3 \%)$ \\
\hline \multirow{2}{*}{$5 \sim 6$} & self & 682 & $104(15.2 \%)$ & $1(0.1 \%)$ & $58(8.5 \%)$ & $24(3.5 \%)$ & $21(3.0 \%)$ \\
years & peers & 319 & $49(15.3 \%)$ & $0(0 \%)$ & $34(10.6 \%)$ & $11(3.4 \%)$ & $4(1.2 \%)$ \\
& educators & 243 & $37(15.2 \%)$ & $0(0 \%)$ & $16(6.5 \%)$ & $10(4.1 \%)$ & $7(2.8 \%)$ \\
\hline
\end{tabular}

The results of different age groups showed that the prevalence of MSL use increased with the participating children's increasing age, taking up $7.2 \%, 7.7 \%$ and $15.2 \%$ of their total language clauses respectively across the three age groups (from the young to old), though the numbers of total language clauses of the three groups were close. There was an obvious disparity between five years and three-andfour years. Five years seemed to be a key point for these Chinese children's MSL development as this age group appeared to use twofold of MSL (104 VS 50) of the younger groups. In terms of MSL types, desire term was mostly used by the children in all age groups $(3.8 \%, 3.3 \%$ and $8.5 \%)$. The tendency of the increasing use of perception and cognition was found to be in line with age growing. The rate of perception and cognition terms raised from $2.0 \%$ to $3.5 \%$, and from $1.2 \%$ to $3.0 \%$ respectively from the youngest to the oldest age group. The term of emotion appeared least with only one record among the participating children's total language of each age group.

Peers in Children's MSL environment showed a similar pattern of MSL use as the focus children did. And there was a trend that the oldest peers contributed significantly more $(15.3 \%)$ MSL talk with the focus children than those of the two younger groups (5.9\% and 6.6\%). Compared with peers, educators constantly produced more MSL in the talk with the 
focus children, yet the oldest group of peers seemed to surpassed educators with slightly higher MSL rate (15.3\% VS $15.2 \%)$. In terms of MSL types, the educators generated more perception terms than the peers (34 VS 22 in total). Differentiated from educators' MSL use, desire expressions dominated the topics $(1.9 \%, 3.6 \%$ and $10.6 \%)$ in the discourses in child-child interactions. The peers' MSL referred relatively less to perceptions and cognition than the educator and this pattern was stable among the three age groups. The use of emotional terms in both educators and peers' language was rare with only 1 instance being identified from the data.

\subsection{The characteristics of MSL referent of focus children}

Table 4 shows referents of children's MSL use in the three age groups. It can be seen from the table that all the focus children were inclined to initiate more MSL talk referring to their peers instead of their educators. With regards of referents in different MSL types, the terms of desire uttered most $(3.6 \%, 2.3 \%$ and $7.9 \%$ ) by the children when talking to their peers.

Table 4. Referents of Children's MSL use in the Three Age Groups

\begin{tabular}{|c|c|c|c|c|c|c|c|c|c|c|}
\hline \multirow{2}{*}{$\begin{array}{c}\text { Age } \\
\text { groups }\end{array}$} & \multirow{2}{*}{$\begin{array}{c}\text { Total } \\
\text { messages }\end{array}$} & \multirow{2}{*}{$\begin{array}{c}\text { Sum } \\
\text { (MSL) }\end{array}$} & \multicolumn{2}{|c|}{ emotion } & \multicolumn{2}{|c|}{ desire } & \multicolumn{2}{|c|}{ perception } & \multicolumn{2}{|c|}{ cognition } \\
\hline & & & sum & referent & sum & referent & sum & referent & sum & referent \\
\hline $\begin{array}{l}3 \sim 4 \\
\text { years }\end{array}$ & 680 & $49(7.2 \%)$ & $1(0.1 \%)$ & $\begin{array}{l}\text { peer: } \\
1(0.1 \%) \\
\text { educator: } \\
0(0 \%)\end{array}$ & $26(3.8 \%)$ & $\begin{array}{l}\text { peer: } \\
25(3.6 \%) \\
\text { educator: } \\
1(0.1 \%)\end{array}$ & $14(2.0 \%)$ & $\begin{array}{l}\text { peer: } \\
11(1.6 \%) \\
\text { educator: } \\
3(0.4 \%)\end{array}$ & $8(1.1 \%)$ & $\begin{array}{l}\text { peer: } \\
3(0.4 \%) \\
\text { educator: } \\
5(0.7 \%)\end{array}$ \\
\hline $\begin{array}{l}4 \sim 5 \\
\text { years }\end{array}$ & 648 & $50(7.7 \%)$ & $1(0.1 \%)$ & $\begin{array}{l}\text { peer: } \\
1(0.1 \%) \\
\text { educator: } \\
0(0 \%)\end{array}$ & $22(3.3 \%)$ & $\begin{array}{l}\text { peer: } \\
15(3 \%) \\
\text { educator: } \\
7(1.0 \%)\end{array}$ & $13(2.0 \%)$ & $\begin{array}{l}\text { peer: } \\
11(1.6 \%) \\
\text { educator: } \\
3(0.4 \%)\end{array}$ & $14(2.1 \%)$ & $\begin{array}{l}\text { peer: } \\
10(1.5 \%) \\
\text { educator: } \\
4(0.6 \%)\end{array}$ \\
\hline $\begin{array}{l}5 \sim 6 \\
\text { years }\end{array}$ & 682 & $\begin{array}{l}104 \\
(15.2 \%)\end{array}$ & $1(0.1 \%)$ & $\begin{array}{l}\text { peer: } \\
19(0.1 \%) \\
\text { educator: } \\
0(0 \%)\end{array}$ & $58(8.5 \%)$ & $\begin{array}{l}\text { peer: } \\
54(7.9 \%) \\
\text { educator: } \\
4(0.6 \%)\end{array}$ & $24(3.5 \%)$ & $\begin{array}{l}\text { peer: } \\
24(3.5 \%) \\
\text { educator: } \\
0(0 \%)\end{array}$ & $21(3.0 \%)$ & $\begin{array}{l}\text { peer: } \\
19(2.7 \%) \\
\text { educator: } \\
2(0.3 \%)\end{array}$ \\
\hline
\end{tabular}

An interesting tendency is that children's MSL containing perception and cognition terms and referring to their peers increased from $1.6 \%$ to $3.5 \%$ and from $0.4 \%$ to $2.7 \%$ respectively, whereas those referring to educators decreased from $0.4 \%$ to $0 \%$ and from $0.7 \%$ to $0.3 \%$. The only three emotion terms appeared in children's language were all appeared in the talk to their peers. To conclude, the focus children showed more capabilities and inclination of using different types of MSL with their age growing. It was noticeable that the children preferred to talk about their desires than other MSL terms. Both peers and educators were important contributors to the focus children's MSL experiences though their MSL input presented in different types. Educators played a more important role in MSL input in the children's language environment, yet the focus children seemed to use more MSL in the talk with their peers and the tendency accelerated with age increasing.

\section{Discussion}

Our study reveals the developmental feature of Chinese children's MSL use in their interactions with peers and educators in preschools. As a pioneering study to explore Chinese children's MSL use, the results increase our understandings about Chinese preschool children's MSL use that may have certain aspects differing from those of Western children. This study shows that five-year-old uttered significantly more MSL than the two younger groups and demonstrated a shift from predominantly use of desire terms to a more balanced pattern containing terms of perceptions and cognition. The milestone change seems to be happened at five years, which is one year later than studies undertaken in Western country that claimed four years is the critical period for the obvious improvement of children's MSL use. We suppose this is due to the two different language systems and the language environments of the two cultures. Chinese adults tended to use less MSL with perception and cognition terms than Westerners in their interactions with young children [2]. This may lead to the later appearance of these two types of MSL in Chinese children's early language experiences. In addition, the cognition terms such as "think", "believe", "know" are more likely to be applied in formal situations in Chinese communication culture [14], and this could restrict the early exposure of this type of language to Chinese children as their parents or educators may regard it is too serious to talk a young child using these terms. One of interesting findings in this study is that the term of desire dominated in children's MSL whereas emotions were expressed least across all the three age groups. This finding resonates the observations from other studies that Western preschoolers also discuss their desires most frequently in conversations with others [7][10][14]. Children seem to have the nature to talk about their desires regardless in Chinese or Western contexts. The least 
use of emotions in children's language appeared to be in line with some Western studies as well [14][17]. However, the absence of emotional expression is more noticeable in our study. We think this result is associated with Chinese culture that suppresses direct and frequent expressions of own or others' emotions. This study was undertaken in preschools where both of peers and educators are important contributors to the focus children's language experiences. It can be seen that educators contributed considerable MSL though their conversations with children, though the older children engaged more child-child talk at five years. The pattern of the educators' MSL was more balanced than children in terms of higher rate of the use of cognition terms. Our finding confirms that educators play a critical role in promoting children's MSL experiences in preschools as many studies claimed [5][8][16]. This is especially the case to the younger groups whose peer talk was comparatively limited than those of the older group. The investigation of peer conversations is a unique part of this study. The peers showed the same changes as the focus children in terms of the amounts and types of MSL with their age grows, except the use of cognition term that kept at a low rate in all the age groups. Relevant research found that children can improve their MSL skills in conversations with peer friends who use MSL frequently [6][7]. There seems to have a assimilation among children's language use. Moreover, peers' talk and MSL use increased significantly in the oldest group, which indicates the peers gradually have more effects on the focus children's language experiences when they are at five years. Another significant finding of this study regards the referent of the focus children's MSL that was mainly related with their peers. This finding suggests that children's MSL output is more likely to be appeared in child-child interactions rather than child- educator interactions. We propose that the free play context may trigger the children's communications relating to their ideas and desires, as other studies also discovered [7][9][10][11]. This finding indicates creating opportunities for children to have free plays and spontaneous talk is important for children to practice their language skills.

\section{Conclusions and Limitations}

We discover that age of five years might be the critical time for Chinese children to improve their MSL use. It highlights the important roles of educators and peers in their contributions to preschool children's MSL experiences, though their MSL language utterances showed different styles and varied across different age groups. The educators generally created opportunities for all children to expose to different types of MSL. Peers, however, provided opportunities for children to practice MSL during their free play, and this is more obvious among the children at five years old. These findings suggest that whilst we need to pay attention to the quantity and quality of educators' language that is crucial to children, the opportunities for peer interactions cannot be undervalued, especially for those at or above five years old. The weakness of this study lies in the limited participants which cannot represent the complex MSL experiences of Chinese preschoolers. Future studies that engage more participants would provide more robust evidence in this field. Further explorations on the strategies that educators can employ for supporting children's MSL development or encouraging effective peer interactions would enrich this research field. References

\section{References}

[1] K. Milligan , J. W. Astington, and L. A. Dack, "Language and Theory of Mind: Meta-Analysis of the Relation Between Language Ability and False-belief Understanding", Child Development, Wiley Blackwell Publishing, United Kingdom,2007, pp.622-646.

[2] S. Degotardi , F. Han, and J.Hu , "Infant educators' use of mental-state talk in Australia and China: A cross cultural comparative study", International Journal of Early Years Education, Taylor and Francis, United Kingdom, 2021, pp.107-122.

[3] D. R. Olson and J. W. Astington, " Thinking About Thinking: Learning How to Take Statements and Hold Beliefs", Educational Psychologist, Taylor and Francis, United Kingdom,1993,pp.7-23.

[4] P. L. Harris, M. D. Rosnay, and F. Pons, "Language and Children's Understanding of Mental States", Current Directions in Psychological Science, Wiley Blackwell Publishing, United Kingdom, 2005, pp.14: 69.

[5] E. M. Barnes and D. K. Dickinson, "Relationships Among Teachers' Use of Mental State Verbs and Children's Vocabulary Growth" ,Early Education And Development ,Taylor and Francis, United Kingdom, 2018,pp. 307-323.

[6] J. R. Brown and N. Donelan-McCall, "Why Talk about Mental States? The Significance of Children's Conversations with Friends, Siblings, and Mothers", Child Development, Wiley Blackwell Publishing, United Kingdom, 1996, pp.836-849.

[7] M. Ziv, M. L. Smadja and D. Aram, "Mothers' and Teachers' Mental-State Discourse With Preschoolers During Storybook Reading", Journal of Cognitive Education and Psychology, Springer Publishing, New York, 2014. pp.103-119.

[8] R. Andrews, P. V. Bergen and S. Wyver, "Use of Mental State Language during Educator-Child and Mother- Child Conversations about the Past and Future", Early Education and Development, Taylor and Francis, United Kingdom, 2020, 31(6), 838-853. 
[9] C. Hughes and J. Dunn, “'Pretend you didn't know': Preschoolers' talk about mental states in pretend play", Cognitive Development, Ablex Publishing, London,1997, pp. 477-497.

[10] V. Ornaghi, J. Brockmeier, and I. G. Gavazzi, "The Role of Language Games in Children's Understanding of Mental States: A Training Study", Journal of Cognition and Development, Taylor and Francis, United Kingdom, 2011,pp.239-259.

[11] L. A. Ribeiro, H. D. Zachrisson, and E. Dearing, "Peer effects on the development of language skills in Norwegian childcare centers", Early Childhood Research Quarterly, Elsevier Science, Netherlands, 2017, pp.1-12.

[12] M. Shatz, H. M. Wellman, and S. Silber, "The acquisition of mental verbs: A systematic", Cognition, Elsevier Science, Netherlands, 1983,pp.301-321.

[13] Bartsch, K. and H. M. Wellman, Children Talk About The Mind, Oxford University Press, New York,1995,pp.143-144.

[14] T. Tardif and H. Wellman, "Acquisition of Mental State Language in Mandarin- and Cantonese-Speaking Children", Developmental Psychology, American Psychological Association, US, 2000, pp.25-43.

[15] A. L. Cutting and J. Dunn, "Theory of Mind, Emotion Understanding, Language, and Family Background: Individual Differences and Interrelations", Child Development, Wiley Blackwell Publishing, United Kingdom,1999, pp.853-865.

[16] K. L. Frampton, M. Perlman, and J. M. Jenkins, "Caregivers' use of metacognitive language in child care centers: Prevalence and predictors", Early Childhood Research Quarterly, Elsevier Science, Netherlands, 2009,pp.248-262.

[17]L. Sheng, W. Dong , and J. Hu, “ Mental state language in Chinese educator-infant conversational interactions during structured and free play", Early Years , Taylor and Francis, United Kingdom,2021,pp.1-16. 